\title{
CULTO ÀS TRADIÇÕES HISTÓRICAS X GASTO PÚBLICO: UM DILEMA DE UMA INSTITUIÇÃO DE ENSINO SUPERIOR MILITAR
}

CULT OF HISTORICAL TRADITIONS X PUBLIC SPENDING: A DILEMMA OF AN INSTITUTION OF MILITARY HIGHER EDUCATION

\author{
ANTONIO JOÃO DE OLIVEIRA VIANNA JUNIOR ${ }^{1}$ \\ BRUNO BRETTAS FRANCO ${ }^{2}$ \\ ELEN MAIARA DOS SANTOS REIS ${ }^{3}$ \\ JÚLIO CÉSAR ANDRADE DE ABREU 4
}

\begin{abstract}
RESUMO: A narrativa apresenta o dilema de um Comandante de uma Escola Militar cujos valores do culto aos heróis e as tradições são materializados por meio do uso de um uniforme histórico peculiar. O questionamento paira sobre o pensamento do comandante, que tem de decidir entre realizar mudanças que acarretam uma economia significativa nos cofres públicos e uma gestão logística mais eficiente, ou manter a sistemática atual em prestígio às tradições. Neste contexto, alterar a estratégia de aquisição e gestão dos referidos uniformes coloca em risco a apresentação individual dos alunos, principal cartão de visitas na recepção de autoridades e civis, que constantemente inspecionam e orientam o estabelecimento de ensino. A redução do emprego de recursos públicos pode causar prejuízos à própria carreira do comandante, pois sua avaliação por superiores pode ser influenciada. E agora? Como agir?
\end{abstract}

Palavras Chaves: Eficiência da Gestão Pública; Cultura Organizacional; Gastos Públicos

ABSTRACT: The narrative presents the dilemma of a Commander of a Military School whose values of worship to heroes and traditions are materialized through the use a peculiar historical uniform. The questioning hinges on the thinking of the commander who has to decide between making changes that lead to significant savings in public coffers and more efficient logistics management or maintaining the current system in prestige to the traditions. In this context, changing the strategy of acquiring and managing such uniforms puts at risk the individual presentation of the students, the main visiting card in the reception of authorities and civilians who constantly inspect and guide the teaching establishment. Reducing the use of public resources can cause harm to the commander's own career because his evaluation by superiors can be influenced. And now? how to act?

Keywords: Efficiency of Public Management; Organizational Culture; Public spending

Data de submissão: 20/06/2018. Data de aceite: 14/12/2018. Data de publicação: 17/12/2018.

\footnotetext{
${ }^{1}$ Especialista em Gestão Empresarial pela FGV e Mestrando em Administração pelo PPGA da Universidade Federal Fluminense.

2 Mestrando em Administração pelo PPGA da Universidade Federal Fluminense.

${ }^{3}$ Mestranda em Administração pelo PPGA da Universidade Federal Fluminense.

${ }^{4}$ Doutor em Administração pela Universidade Federal da Bahia (UFBA), com período de estágio sandwich na Universidade Complutense de Madri, Espanha. Professor Adjunto do Curso de Administração Pública da Universidade Federal Fluminense (UFF) Polo Universitário de Volta Redonda.
} 


\section{INTRODUÇÃO}

Era uma tarde de sexta-feira, em meados de maio de 2016, e o Comandante da Escola Militar, Joaquim José, convoca uma reunião extraordinária para às 15 horas, no auditório principal. A preocupação com os gastos para aquisição dos uniformes escolares dos alunos não poderia continuar "martelando" a sua mente.

- Capitão Jorge! Acione todos os chefes de setores para uma reunião às 15 horas de hoje. Quero resolver essa questão dos uniformes com o assessoramento de todos os principais oficiais desta unidade.

- Sim, senhor Comandante!

$\mathrm{Na}$ reunião se encontravam os assessores e chefes dos principais setores da Escola: Subcomandante, Comandante dos Alunos, Comandante do Setor Administrativo, Oficial de Logística do Estado Maior, Oficial de Pessoal do Estado Maior, Ordenador de Despesas, Chefe da Divisão Administrativa, Chefe do Almoxarifado e Chefe da Seção de Logística dos alunos.

De perfil calmo e de fácil acesso aos seus subordinados, o Comandante Joaquim tinha como missão, na esfera militar, o comando de homens e mulheres de garbo, o que exige uma atuação ilibada e exemplar de liderança. Já como gestor público, este Oficial tinha como principal papel ser o Agente Diretor de uma das Organizações Militares mais importantes de uma Força Armada.

\section{VALOR INSTITUCIONAL DO CULTO ÀS TRADIÇÕES}

Nomeado pelo Comandante Geral das Forças Armadas para comandar este estabelecimento de ensino, Joaquim era o principal vetor de difusão dos valores militares para o futuro da Força, tendo em vista a missão de capacitar futuros oficiais que, por sua vez, difundirão tais valores para todos os rincões do território nacional. Dentre as manifestações dos valores militares, destaca-se o Civismo.

Este pensamento é enraizado no cerne da Força através de normativa interna CC20NR-13.123 - Orientação de Fundamentos da Força Armada. O Civismo é estimulado levando em consideração que os militares são vetores de disseminação da cultura nacional no seio da sociedade brasileira.

Exercido diuturnamente nas inúmeras atividades, o patriotismo é retratado no culto aos heróis e patronos, nas comemorações das solenidades cívico-militares, na preservação da memória militar e das tradições históricas. Especificamente com os alunos desta Escola, a criação e o uso do uniforme histórico é uma distinta homenagem à atuação histórica dos heróis da Força Armada nos combates que participaram no passado.

Nas organizações componentes do Sistema de Ensino da Força Armada, essa preocupação em arraigar os valores nos alunos se faz de forma potencializada, especialmente pelo fato de que se faz oportuno o momento de capacitação e formação militar para substancializá-los.

Após 28 anos de serviços prestados à nação, Joaquim foi selecionado para uma das missões que envolvem mais responsabilidade na carreira das armas e foi escolhido por ser detentor de características essenciais do chefe militar: liderança sobre seus subordinados, preocupação com o auto aperfeiçoamento constante e dedicação à pátria. Dentre cursos militares e civis realizados por Joaquim, destacam-se a conclusão do curso de graduação em Administração e de especializações na área de Direito Público e Gestão Pública, fatores que viabilizaram uma condução cautelosa e apropriada de suas ações administrativas como chefe de organizações militares ao longo de sua carreira. 
Neste último desafio da carreira, Joaquim é colocado à "prova" de todas as ações implementadas pois, ao término da missão, passará por um conselho de Oficiais Marechais que irão avaliar seu desempenho e, conceder ou não, sua promoção ao posto de Oficial Marechal. Toda sua turma já deposita expectativas na sua promoção, por sua postura e conduta no decorrer da profissão, bem como sua família, que o apoiou em todos os momentos de empenho pessoal e profissional para que chegasse ao topo da carreira.

\section{AS PECULIARIDADES DA GESTÃO DOS UNIFORMES HISTÓRICOS}

O uniforme histórico é de uso exclusivo dos atuais alunos, porém, ao longo de toda a história deste Estabelecimento de Ensino, todos os militares que passaram pela escola utilizaram este legendário uniforme, sempre com muito orgulho e vibração, representando assim um marco na vida de cada um. Seu uso é previsto em ocasiões especiais: guardas de honras para autoridades civis e militares, desfiles e paradas, bem como formaturas, solenidades e bailes de gala.

Visando uma apresentação individual primorosa, digna da grandiosidade tradição associada ao uniforme histórico, duas peças do fardamento - túnica e calça - são habitualmente feitas sob medida para cada um dos cerca de 500 militares que se matriculam todos os anos. Para tal, o tempo de execução do serviço de confecção pelos alfaiates contratados dura em torno de 5 meses, entre medições, provas e ajustes.

Conforme indicado, o uniforme é feito sob medida para cada militar e, assim sendo, requer um minucioso planejamento dos alfaiates para que tudo fique em conformidade com o previsto. É exigida atenção com cada detalhe do tecido, o brilho dos botões, alinhamento das ombreiras, comprimento das mangas e calça tem de estar corretos, nos mínimos detalhes.

Devido a todos esses fatores, aliados à redução do número de alfaiates especialistas no mercado, o interesse pelo fornecimento do uniforme foi sendo perdido pelas empresas que atuam no ramo. Nos últimos anos, a concorrência tem diminuído significativamente entre os poucos empresários que ainda permanecem confeccionando o uniforme histórico. Neste contexto, a Tabela 1, no anexo, representa o custo atual do uniforme completo para um militar.

Por meio de uma conta simples, multiplicando o valor unitário total do uniforme (R\$ $2.018,36)$ pela quantidade estimada de alunos $(500)$, tem-se uma previsão de custo que ultrapassa o valor de $\mathrm{R} \$ 1.000 .000,00$ (um milhão de reais).

Aliado a isto, devido à rotina intensa dos alunos, os horários disponíveis para realização das medidas e ajustes necessários são sempre após as aulas: entre as $19 \mathrm{~h}$ e $24 \mathrm{~h}$ nos dias de semana. Como o efetivo discente é estimado em 500 alunos, cada medida e ajuste necessário é realizado ao longo de uma semana inteira, o que implica em custos com alimentação, alojamento e transporte de pessoal por parte da contratada. Esta sistemática implementada, levando em conta a obrigatoriedade da personalização dos uniformes sob medida, gera desgastes dos instrutores e dos alunos que desviam seus horários de estudo para se dedicarem às provas e revistas dos uniformes.

Normas internas da Força Armada indicam a durabilidade de cada peça componente do uniforme, viabilizando uma gestão dos materiais, desde a aquisição, estocagem, à distribuição. Em média, as peças principais que compõem este uniforme têm durabilidade prevista de 4 anos, exatamente o tempo que os alunos passam em formação.

Pesquisas em andamento buscam verificar uma real duração de cada peça dos uniformes, tendo em vista que, após os quatro anos de posse por parte do aluno ocorre a 
devolução para o almoxarifado, que hoje acumula mais de 1.000 (um mil) conjuntos armazenados e que aguardam autorização para incineração.

Por meio de consulta aos usuários, estima-se que, ao longo do período de formação os alunos utilizam o referido uniforme em torno de 8 vezes, e que o desgaste do tecido e das peças componentes seria de baixa relevância. No que tange à manutenção da condição de uso dos uniformes, uma questão frequente é a mudança corporal dos alunos no decorrer do tempo como discentes, o que faz com que busquem reparos e ajustes visando uma adaptação e uma apresentação individual adequada ao status que representam.

Uma alternativa possível para solucionar a questão da logística dos uniformes seria a criação de uma comissão para avaliar os uniformes em depósito, de forma a selecionar as peças que ainda têm condições de uso. Desta forma, aumentaria a durabilidade do uniforme e a necessidade de compra seria reduzida, pois ocorreria apenas para os militares que não se adequassem às peças selecionadas para reuso. Outra opção seria uma alteração na sistemática de aquisição dos uniformes por meio da retirada da exigência da personalização, adotando a sistemática de aquisição de tamanhos padronizados como pequeno, médio e grande.

Essas opções são defendidas pelos assessores técnicos, por acarretar em uma direta economia de meios que, segundo a visão particular do Comandante Joaquim, não acarretaria prejuízos na apresentação individual dos alunos.

\section{E AGORA COMANDANTE?}

A instabilidade política ocasionou uma evidente crise financeira que assola os cofres públicos brasileiros e fez com que os órgãos de controle externo intensificassem a fiscalização e as exigências na condução dos processos licitatórios e gastos públicos. Recentes veiculações na mídia sobre gastos julgados descabidos por organizações militares, aliado ao aumento de imputações de multa à gestores militares pelo Tribunal de Contas da União, fizeram com que todos os atuais comandantes repensassem seus planos de contratações públicas, questionando a real necessidade de cada item a ser licitado.

Desta forma, o Comandante, a fim de realizar uma gestão eficiente e adequada à situação atual, determinou que todos os gastos frequentes e planejados fossem revistos para que se ratificassem suas necessidades. Dentre eles, os gastos com os uniformes escolares ficaram na pauta para serem reafirmados em termos de custo $\mathrm{x}$ benefício e no formato que é feito tradicionalmente.

O Ordenador de Despesas assessora o Comandante visando reduzir os gastos e aumentar a durabilidade do uniforme, propondo o reaproveitamento das peças estocadas que se encontram em condições de uso. Neste sentido, o processo de distribuição dos uniformes se iniciaria por meio da seleção, através de uma comissão de oficiais, das peças armazenadas no almoxarifado. Os alunos recém-chegados no início do ano letivo iriam provar as peças selecionadas, para verificação da compatibilidade com as medidas individuais. Desta forma, seriam adquiridas apenas as peças necessárias aos alunos que não obtiverem êxito na seleção de peças compatíveis, o que se presume uma direta economia no emprego dos recursos financeiros habitualmente utilizados.

Por outro lado, a distinta Escola possui assessores especiais do Comandante, em sua maioria formados na década de 70 e 80 - contemporâneos dos Oficiais Marechais que ocupam as mais altas funções da Força - e que estão em consenso quanto à valorização do uso do uniforme histórico. Estes pressionam o Comandante no sentido de não alterar qualquer processo que envolve a aquisição deste fardamento, por acreditarem que, da 
forma como acontece, destaca-se a apresentação individual dos militares e mantém a tradição secular envolvida.

Outro aspecto a ser levado em conta é que, caso qualquer mudança implementada prejudique a apresentação individual dos alunos perante às solenidades de recepção de autoridades civis e militares, o Comandante Joaquim pode ser responsabilizado, fato este que prejudicaria sua "campanha" para a promoção de posto no próximo ano. Expor a unidade militar às observações negativas de visitantes e superiores, além de prejudicar a imagem da instituição como um todo, seria fatalmente alvo de cobrança na escala hierárquica.

A ameaça à promoção de Joaquim faz com que seja colocado em risco os planos pessoais deste militar de implementar uma nova sistemática na Administração e Gestão Militar, baseada essencialmente no aprimoramento técnico-profissional obtido.

Ademais, não se pode olvidar que o antigo comandante da Escola permaneceu por dois anos no cargo e não implementou nenhuma mudança na sistemática do uniforme histórico e, atualmente, ocupa um cargo de direção à qual a escola está diretamente subordinada.

Vale destacar a preocupação da Instituição para com o assunto que, mesmo com cortes orçamentários, em nenhum momento restringiu ou diminuiu a descentralização de recursos financeiros para as atividades relativas à aquisição de uniformes, exatamente por considerar a importância do culto às tradições. Desta forma, a questão evidenciada não se traduz por indisponibilidade de dinheiro ou necessidade de redução, mas sim de gestão de recursos públicos.

Nota-se claramente a existência de dois grupos de influência: assessores técnicos capitaneados pelo Ordenador de Despesas, que primam essencialmente pela aplicação adequada dos recursos públicos em um contexto de frequentes escândalos de corrupção veiculados pela mídia brasileira; e, por outro lado, o grupo dos assessores políticos composto por militares da reserva e da ativa, com atuação influente no alto escalão da força, que defende o pensamento clássico institucional de apoio irrestrito e imensurável à manutenção das tradições militares.

Ultrapassar este obstáculo é necessário para que Joaquim alcance posições mais altas e, por consequência, consiga implementar mudanças primordiais para a Administração Militar. Em meio a um dilema decisório pertinente e atual, o Comandante precisa de atributos como responsabilidade, comprometimento e visão de futuro para tomar a decisão mais acertada para si e para o futuro da Força Armada.

Neste contexto, discuta acerca das questões abaixo:

1.Como você analisa a relação dos uniformes com o culto às tradições institucionais?

2.Como você analisa os riscos de se reutilizar os uniformes que se encontram no almoxarifado?

3. Diante de uma recente exposição na mídia do fato, indicando um eventual mau uso de recursos públicos, quais ações poderão ser sugeridas para desenvolver uma gestão mais adequada dos recursos?

4.Quais os riscos e os benefícios envolvidos nas possíveis decisões do Comandante? 


\section{ANEXOS}

Tabela 1 - Composição de Custos dos Itens do Uniforme Histórico

\begin{tabular}{|l|c|c|c|}
\hline \multicolumn{3}{|c|}{ Composição de Custos dos Itens do Uniforme Histórico } \\
\hline \multicolumn{1}{|c|}{ Item } & Quant & $\begin{array}{c}\text { Valor } \\
\text { Unitário }\end{array}$ & Valor total \\
\hline Camisa branca & 1 & $\mathrm{R} \$ 64,98$ & $\mathrm{R} \$ 64,98$ \\
\hline Luva preta & 1 & $\mathrm{R} \$ 8,00$ & $\mathrm{R} \$ 8,00$ \\
\hline Meia de nylon preta & 1 & $\mathrm{R} \$ 4,26$ & $\mathrm{R} \$ 4,26$ \\
\hline Polaina dourada & 1 & $\mathrm{R} \$ 22,95$ & $\mathrm{R} \$ 22,95$ \\
\hline Sapato & 1 & $\mathrm{R} \$ 69,99$ & $\mathrm{R} \$ 69,99$ \\
\hline Barretina Branca com penacho & 1 & $\mathrm{R} \$ 410,00$ & $\mathrm{R} \$ 410,00$ \\
\hline Cinto histórico & 1 & $\mathrm{R} \$ 45,95$ & $\mathrm{R} \$ 45,95$ \\
\hline $\begin{array}{l}\text { Cordão e passadores c/ palmatorias e borlas com franjas } \\
\text { verdes }\end{array}$ & 1 & $\mathrm{R} \$ 173,59$ & $\mathrm{R} \$ 173,59$ \\
\hline $\begin{array}{l}\text { Conjunto uniforme histórico Masculino, constituído de: } \\
\text { 01 (uma) túnica e 01 (uma) calca, sob medida, em tecido } \\
\text { poliéster e lã, sarja (55\% poliéster e 45\% lã); e 02 (duas) } \\
\text { charlateiras }\end{array}$ & & & \\
\hline Distintivo metálico dourado: em miniatura & 1 & $\mathrm{R} \$ 959,99$ & $\mathrm{R} \$ 959,99$ \\
\hline Ferragens para cinto histórico, com 13 pecas & 2 & $\mathrm{R} \$ 2,80$ & $\mathrm{R} \$ 5,60$ \\
\hline Quepe branco completo & 1 & $\mathrm{R} \$ 150,00$ & $\mathrm{R} \$ 150,00$ \\
\hline Talim, jogo c/ duas guias & 1 & $\mathrm{R} \$ 84,00$ & $\mathrm{R} \$ 84,00$ \\
\hline \multicolumn{1}{|c|}{ Total } & $\mathrm{R} \$ 19,05$ & $\mathrm{R} \$ 19,05$ \\
\hline
\end{tabular}

Fonte: Elaborado pelo autor com base no portal comprasgovernamentais.gov.br

\section{NOTA DE ENSINO}

\section{OBJETIVO DE ENSINO}

O caso em questão alinha-se aos conceitos correlacionados às temáticas da eficiência dos gastos públicos, governança pública e cultura organizacional.

\section{APLICABILIDADE}

Os conceitos relacionados podem ser aplicáveis a cursos de graduação e pósgraduação/MBAs, que envolvam disciplinas como cultura organizacional, licitações, contratos e convênios, direito administrativo e gestão pública.

\section{DINÂMICA}

A dinâmica a ser implementada em sala de aula é sugerida em consonância com o Roteiro 01:

Roteiro 01- Divisão da turma em dois grupos de igual efetivo, sendo um grupo defensor das mudanças e um segundo grupo contrário a qualquer mudança. Após tempo de leitura e discussão interna nos grupos, cada um deles apresenta seus argumentos que sustentam as opiniões impostas, proporcionando-se, assim, o debate no âmbito de toda a turma. 
Quadro 1 - Proposta de Plano de Aula Roteiro 01

\begin{tabular}{|c|c|c|c|}
\hline Ordem & Atividade & Duração & Observações \\
\hline 1 & Apresentação da dinâmica de aula & 5 minutos & $\begin{array}{l}\text { Apresentar o objetivo do estudo e } \\
\text { a correlação com a disciplina }\end{array}$ \\
\hline 2 & Divisão dos grupos & 5 minutos & $\begin{array}{l}\text { Explicar a dinâmica da aula e } \\
\text { implementar a divisão dos } 2 \\
\text { grupos, impondo-lhes as posições } \\
\text { a serem sustentadas (a favor de } \\
\text { mudanças e contrário às } \\
\text { mudanças) }\end{array}$ \\
\hline 3 & $\begin{array}{c}\text { Leitura pelos componentes dos } \\
\text { grupos e debate da defesa dos } \\
\text { argumentos afetos à posição } \\
\text { designada }\end{array}$ & 45 minutos & $\begin{array}{l}\text { Debate entre os membros do } \\
\text { grupo e consolidação dos } \\
\text { argumentos de defesa das } \\
\text { posições impostas. }\end{array}$ \\
\hline 4 & $\begin{array}{l}\text { Apresentação dos argumentos e } \\
\text { posições de cada grupo }\end{array}$ & 60 minutos & $\begin{array}{l}\text { Cada grupo terá } 15 \text { minutos iniciais } \\
\text { para apresentar o resultado de seu } \\
\text { debate de forma geral. Após isso, } \\
\text { iniciando pelo grupo de posição } \\
\text { contrário às mudanças, cada grupo } \\
\text { terá } 5 \text { minutos para apresentar sua } \\
\text { resposta às perguntas do caso. } \\
\text { Continuamente serão concedidos } \\
3 \text { minutos para réplica do grupo } \\
\text { contrário e } 2 \text { minutos para a } \\
\text { tréplica final. }\end{array}$ \\
\hline 5 & $\begin{array}{c}\text { Análise do caso e considerações } \\
\text { finais }\end{array}$ & 30 minutos & $\begin{array}{l}\text { Destacar os apontamentos } \\
\text { indicados pelos grupos e enfatizar } \\
\text { algum outro aspecto não } \\
\text { correlacionado. Indicar uma } \\
\text { resposta para a questão: Qual } \\
\text { decisão o Comandante Joaquim } \\
\text { deve tomar? }\end{array}$ \\
\hline
\end{tabular}

\section{NOTA TEÓRICA}

\section{a) Valores e Cultura Organizacional}

Segundo Schein (1992), a denominação cultura é empregada para designação de pressupostos básicos e crenças aquinhoadas pelos membros de uma mesma organização, que se baseia em um padrão de hipóteses referenciadas, as quais se apresentam eficazes na resolução de problemas de adaptação externa e integração interna.

Srour (1998, p. 174), esclarece o entendimento sobre cultura organizacional "[...] a cultura é aprendida, transmitida e partilhada. Não decorre de uma herança biológica ou genética, porém resulta de uma aprendizagem socialmente condicionada. A cultura organizacional exprime então a identidade da organização. [...]"

Já Silva Neto et al (2009), aponta que "os valores dos líderes e fundadores indubitavelmente moldam a cultura, porém é por meio das práticas diárias, transmitidas aos membros mediante mecanismos de socialização, que essa cultura afeta seus membros, 
razão pela qual as percepções compartilhadas de tais práticas constituem a essência da cultura de uma organização."

b) Eficiência e Gestão pública

A aptidão em obter a maior produção de bens e/ou serviços com a mínima utilização de insumos ao menor custo operacional possível, sem que haja o comprometimento da qualidade, pode ser caracterizada como uma definição ampla de eficiência. Esta definição se alinha ao alcance de uma relação custo-benefício, por meio da conquista de níveis máximos de produção, empregando níveis mínimos de recursos. A eficiência objetiva-se significativamente através da conformação dos sistemas de produção ao devido alcance dos objetivos definidos (ROCHA, 1990; TCU, 2000; INTOSAI, 2004).

Silva (2007) aponta que "O princípio da eficiência administrativa consiste na organização racional dos meios e recursos humanos, materiais e institucionais para a prestação de serviços públicos de qualidade em condições econômicas e de igualdade dos consumidores".

Meirelles (2002) evidencia a importância da correlação do princípio da eficiência com o exercício da atividade administrativa, destacando a necessidade da presteza, da perfeição e do rendimento funcional, bem como um empenho em não se limitar ao estrito cumprimento legal, buscando efeitos positivos tanto para o serviço público como para a satisfação dos atores da comunidade.

\begin{abstract}
é de se perquirir o que muda com a inclusão do princípio da eficiência, pois, ao que se infere, com segurança, à Administração Pública sempre coube agir com eficiência com seus cometimentos. Na verdade, no novo conceito instaurado de Administração Gerencial, de 'cliente', em lugar de administrado, o novo 'clichê' produzido pelos reformadores, fazia-se importante, até para justiçar perante o país as mudanças constitucionais pretendidas, trazer ao texto o princípio da eficiência. Tais mudanças, na verdade, redundaram em muito pouco de substancialmente novo, e em muito trabalho aos juristas para tentar compreender figuras emprestadas sobretudo do Direito Americano, absolutamente diferente do Direito Brasileiro (FIGUEIREDO, 2001, p. 63).
\end{abstract}

Slomski (2005) ratifica o ideal de que a eficiência diz respeito não apenas com a menor quantidade de recursos empregados na produção de serviços e produtos para uma sociedade, mas também na relação de expectativa no que tange à tempestividade e qualidade, cabendo à administração pública a capacidade de prover a partir do que foi pleiteado pela coletividade, proporcionando por consequência o bem-estar social.

\title{
REFERÊNCIAS
}

BRASIL. Tribunal de Contas da União. Técnicas de auditoria: indicadores de desempenho e mapa de produtos. Brasília: TCU. 2000.

CHIAVENATO, I. Recursos humanos na empresa: pessoas, organizações e sistemas. 3.ed. São Paulo: Atlas, 1994. p. 67-76.

FIGUEIREDO, L. V. Curso de direito administrativo. São Paulo: Malheiros, 1994, p. 281.

INTOSAI. Guidelines for internal controls standards for the public sector. 2004. http://www.intosai.org/Level3/Guidelines/3_InternalContrStand/3_GuICS_PubSec_e.pdf 
MEIRELLES, H. L. Direito administrativo brasileiro. São Paulo: Malheiros, 2002, p.94.

ROCHA, A. C. A função da Auditoria Operacional na avaliação de controle de Entidades Governamentais. Revista do TCU. V. 44, abr./jun. 1990.

SCHEIN, E. H. Organization culture and leadership. 2nd ed. São Francisco: Jossey-Bass, 1992.

SILVA, J. A. da. Comentário contextual à Constituição. 4. ed. São Paulo: Malheiros, 2007. p. 342.

SILVA NETO, J. M.; PEREIRA, S. A.; MATOS, D. S.; LOCKS, R. Teorias da Semiótica e Cultura Organizacional: estudo em uma instituição militar do Exército Brasileiro. Revista de Contabilidade do Mestrado em Ciências Contábeis da UERJ, v. 14, n. 1, art. 2, p. 1-13, 2009.

SLOMSKI, V. Controladoria e governança na gestão pública. São Paulo: Atlas, 2005. SOUZA, A. C.; FIALHO, F. A. P.; OTANI, Nilo. TCC: métodos e técnicas. Florianópolis: Visualbooks, v. 2007, 2007.

SROUR, R. H. Poder, cultura e ética nas organizações. Rio de Janeiro. Campus, 1998. 